\title{
Appreciative evaluation of restorative approaches in schools
}

A restorative approach to conflict is being increasingly applied in schools around the world. Existing evaluation evidence has tended to focus on the impact on quantifiable outcomes such as number of behaviour incidents and rates of attendance and exclusion. This case-study aimed to broaden the evidence base to capture a richer picture of the implementation and impact of restorative approaches from the perspective of a selection of staff in one inner-London primary school. The study adopted Appreciative Inquiry as the evaluation methodology in order to engage the participants in a meaningful and educative evaluation process. The staff reported with honesty and insight on the complexities of adopting restorative practice in their busy and demanding work context. They identified when, how and why restorative practice works well at their school. The outcomes reported include the impact of RA on climate for learning, life skills, emotional literacy, behaviour and relationships more broadly, and more specifically the impact on speaking, listening, thinking and conflict resolution skills. They equally reported on when and why it is not always either possible or appropriate to engage in a restorative response to conflict. The findings of this evaluation highlight the importance of congruence between the values, practice and outcomes and between different members of the school community. The findings are discussed in relation to other evaluation reports and also in terms of their implications for restorative practitioners and researchers.

Keywords: restorative practice; evaluation; appreciative inquiry; school

Restorative Approaches at our school...it's like a polar bear watching over the water hole, waiting, thinking, thinking this is it, this is the moment we can make the difference, catch the fish, change things. (Deputy Headteacher)

\section{Introduction}

Restorative practice is being increasingly adopted in schools as an alternative way of responding constructively to conflict. School staff working with restorative practice 
have reported that it is more than a behaviour management tool, that there is a deeper and richer philosophy of life that this work expresses (Morrison \& Vaandering, 2012). The present study aimed to explore in depth how RA was functioning in one primary school from the perspective of a selection of the school staff.

Restorative practice has its roots in restorative justice, which is an alternative to the punitive paradigm within the field of criminology. Restorative Justice is primarily focused on some form of mediated encounter between the perpetrator and victim following an incident of harm. The principles underpinning restorative justice are now being more widely applied to practice in a variety of non-judicial settings including schools, where they are referred to as restorative practice (RP) or more broadly as restorative approaches (RA) (Thorsborne \& Vinegrad, 2006).

Restorative practice has a relatively short but fast moving history in schools and is now implemented in many countries, principally but not exclusively in New Zealand, Australia, Canada, the United States of America and the United Kingdom. This definition offered by Mark Corrigan (2012, p. 3) captures the more holistic sense of RP in the school setting:

\footnotetext{
Restorative Practice is a philosophy, in action, that places the relationship at the heart of the educational experience. Restorative work in school communities builds and maintains inclusive networks of positive relationships. A range of specific restorative tools are used to restore these relationships where harm and misconduct occur.
}

Typically, RP in schools consists of the use of a common language around harm, so that where misbehaviour and conflict occur the focus is on staff, and ideally pupils too, seeking to understand what happened, who has been affected and how, what is needed for things to be put right and what has been learned from this incidence of conflict to reduce the risk of further harm. This practice can happen informally in the 
day-to-day flow of the school life, in the corridor, classroom or on the playground. It can also take a more formalised form through restorative conferencing or peer mediation.

As RA has been increasingly adopted by schools, so there has emerged a body of evaluation evidence reporting on its impact. Within the UK at least, the three most widely cited evaluation reports can all be described as outcome evaluations, focusing on the impact of RA on common quantifiable variables such as rates of attendance, numbers of reported behaviour incidents and number of exclusions (YJB, 2004; Kane, Lloyd, McCluskey, Riddell, Stead, \& Weedon, 2008; Skinns, Du Rose \& Hough, 2009). Whilst this focus on measurable outcomes has been useful in establishing a basis of credibility, which has helped to promote the growth of restorative work in schools, this evidence reports on only part of what there is to be known.

Given that RA grew from restorative justice, it may be useful to return to the roots of restorative justice to identify what evaluations of RA in schools could be looking to evaluate. The grandfather of restorative justice, Howard Zehr reminds us that, "Restorative justice is not primarily designed to reduce recidivism" (2002, p. 9), he states that the positive impact of restorative justice on reducing reoffending is a byproduct and that the core reason for working restoratively is because, "it is the right thing to do" (p.10). The primary focus on similar by-products in existing evaluations of school-based RA may be seen as distractions from the essence of restorative work, which has been described as, "addressing basic social and emotional needs of individuals and communities" (Morrison, 2007, p. 73). The present study is an attempt to return to the roots of restorative work and to explore ways of drawing out people's experiences of some of these more humanistic aspects of RA. 
In their large scale evaluation of the implementation and impact of RA across 18 Scottish schools, Kane et al hint in the penultimate sentence of their conclusion at something more humanistic about RP, "Restorative Practices encouraged connection at a deeper and more personal level than many other educational initiatives" (2008, p. 248). There is, however, no support or explanation provided for this assertion. The limitations of the more standardised evaluation methods applied in the above studies lie partly in their apparent inability to capture data that address those less easily measurable aspects of RA in schools. Appreciative inquiry (AI) was adopted as the evaluation methodology for the present study in an attempt to draw a "deeper and more personal" picture of RA in one primary school.

The essence of appreciative evaluation is captured by Coghlan, Preskill and Tzavaras Catsambas, "Instead of focusing on problems, organizational members first discover what is working particularly well in their organization. Then, instead of analyzing possible causes and solutions, they envision what it might be like if "the best of what is" occurred more frequently" $(2003$, p. 6). The selection of AI was motivated by a curiosity about its potential usefulness for the participants and for the purposes of the evaluation. Accounts from the literature have reported on the capacity for AI to engage programme participants in structured processes of individual and joint reflection, with an emphasis on the assets of the person, the programme and the organisation to achieve rich and sometimes unexpected findings (Elliott, 1999; Jacobsgaard, 2003). It was therefore hoped that using this methodology might enable something of the deeper and more personal picture of RA in schools to emerge.

\section{Method}

This article describes the process of the appreciative evaluation as it was conducted with six volunteer participants at one inner-London primary school. The purpose of this 
evaluation was to explore in depth people's 'experiences, perceptions, opinions, feelings, and knowledge' (Patton, 2003, p. 2) of restorative approaches in their school.

The evaluator had a pre-existing relationship with the school as the local authority officer who had supported the school with the implementation and development of RA. The aims of this evaluation were not to prove that RA works, but rather to explore in detail what the implementation and impact was from the perspective of school-based practitioners. Therefore, following Pole (1993) the evaluator's knowledge and advocacy of RA are incorporated as a positive contaminant to this evaluation process.

The site of this case study is a mixed primary school in a central London borough. There are 355 pupils on roll and the school serves one of the 20 most deprived of 624 wards in London, with $30 \%$ of pupils are eligible for free school meals, which is well above the national average. Most pupils come from a broad range of minority ethnic backgrounds and $66 \%$ of pupils have English as an additional language, which is also well above the national average. The KS1-2 Value Added Score places the school among the top $5 \%$ of primary schools nationally. The school was judged Outstanding in its most recent Ofsted inspection report. The school places a strong value on the social and emotional wellbeing of its pupils alongside academic excellence.

It was considered to be more useful, given the purposes of the evaluation, to study a school that had a history of engagement with RA. For practical reasons, with regard to time and volume of data, the number of staff who could participate was restricted to six. The rationale for participant selection was to create a sample that was a cross-section of the staff group in terms of role in order to include a range of perspectives. The group of six voluntary participants comprised two Teaching Assistants, two Teachers, and two members of the Senior Management Team. The 
participants were not balanced in terms of gender, the group comprising five women and one man.

This group of six staff engaged in the four phases of the appreciative evaluation process over a period of four months, as described below. The Appreciative Inquiry process is divided into four I-phases: Inquire (appreciative interviews); Imagine (create a vision of future success); Innovate (develop provocative propositions); and Implement (create plan of action).

\section{Phase 1 Inquire}

The Inquire phase of the AI process consisted of individual semi-structured interviews with the volunteer participants. Each interview lasted between 30 and 50 minutes and the questions were devised to draw out the three core foci: peak experience, values and wishes. The questions relating to each focus explore respectively:

- Peak experience - what have been the participant's best moments in relation to the programme (e.g. Talk to me about the Restorative Approaches work that the school has been doing, what happens, what has your involvement been, what have the outcomes been?);

- Values - connections between people's experience of the programme and their personal values (What is most important to you about the work that you do?);

- Wishes - what the 'best of' would look like (If you could transform the way you do your work, what would it look like and what would it take to make it happen?).

One of the most challenging questions, 'If Restorative Approaches were an animal, what animal would it be?' provided a selection of entertaining and revealing responses, such as the one that heads this paper. 
The interviews were recorded and then subjected to a methodical process of data transcription, coding, analysis and synthesis. The considerations that informed the choice of approach to the data analysis were both practical and philosophical.

Practically, there was a very large body of data to analyse, and it was important for me to be faithful to that data whilst at the same time keeping the study on track so that there would not be too long a hiatus between the interview phase and the subsequent group phase. Philosophically, it was important for the selection of data analysis techniques to be concordant with the theoretical underpinnings of AI, that is, rooted in a social constructionist paradigm.

In my engagement with the interview data I followed the three stage method of coding data proposed by Neuman (2011) of open coding, followed by axial coding followed by selective coding. King and Horrocks (2010) present a not dissimilar threestage coding process termed descriptive coding, interpretive coding and overarching themes. I combined these two processes of coding into a seven-stage sequence: initial open coding; transcription; within-interview open coding (highlighting words, phrases or whole utterances that appeared relevant or interesting, and making descriptive notes); within-interview descriptive coding (defining a set of descriptive codes from the open coding and descriptive notes); across-interviews descriptive coding (identifying patterns across interviews); interpretive coding (identifying the higher level unifying themes and the lower level explanatory themes); and axial coding (structuring the themes into a matrix).

The synthesis of the interview data were presented to the group at the start of the next phase of the appreciative evaluation process. 


\section{Phase 2 Imagine}

Six weeks after the final interview had been completed, the six participants met as a group for two hours with the evaluator to undertake the next phases of the AI evaluation process. Following the discussion of the synthesis from the interviews, when the participants were able to challenge or confirm the analysis of what they had said, they then engaged in the Imagine phase of the AI evaluation process. The participants imagined that two years hence their school had won a national award for their work with this restorative programme and they spent time identifying what would be happening at their school for them to have achieved this award. The pictures, notes and discussion from this Imagine phase formed the basis of the next phase in the evaluation process.

\section{Phase 3 Innovate}

In the Innovate phase, the participants were asked as a whole group to develop provocative propositions, which are affirmative sentences written in the present tense to bridge the best of what is with what could be. One example of a provocative proposition from this group was 'Children are given the tools and the opportunity to resolve their difficulties peacefully'. Provocative propositions resemble outcome indicators from more traditional evaluations; what distinguishes provocative propositions is that they are developed by the evaluation participants.

The evaluator collated and synthesised the provocative propositions that had been drafted before the group moved on to the next phase.

\section{Phase 4 Implement}

Three weeks after the previous session, the group met again with the evaluator to work through the Implement phase. This phase represents the formulation of the plan to act 
on the provocative propositions. In this group session, the six participants refined and finalised the provocative propositions, and agreed what and how they would feed back to the whole school staff team at a staff meeting later in the term.

Then three weeks after the Implement group session, the participants presented to the staff team what they had learned through the AI evaluation process, and they presented their recommendations (in the form of the provocative propositions) for discussion. The recommendations were refined with the whole staff team and taken by a member of the senior leadership team to feed into the action plan for RA at the school for the following school year.

\section{Findings and Discussion}

RA is one field of educational innovation that can be charged with high rhetoric regarding the rightness of the approach and the transformational benefits it promises to offer (Cremin, 2013). The staff at this school in this study expressed neither a romantic idealism nor a cynical dismissal, but rather a realistic, hopeful stance. The tone of the findings was very much one of grounded honesty. Their perspective acknowledged that emotions are real, should be recognised and known how to be dealt with; that conflicts happen, and that conflicts present an opportunity for a constructive way forward; that life in school can be difficult, and therefore strategies are needed. Their conclusion was that the restorative work at their school opens up alternative and more constructive ways of dealing with emotions, with conflict and with life more generally.

A clear theme that emerged from the data was congruence, which functioned at a variety of levels. 


\section{Congruence in values}

It was identified that the school's values needed to be in alignment with restorative values. The values that were articulated as the school's values (e.g. honesty, trust, responsibility and fairness) were considered to be embodied in restorative ways of working. Just as restorative practice promoted and enacted the school's values so the school's values enabled restorative practice to flourish. There was a symbiotic relationship between the school's ethos and restorative practice.

\section{Congruence in practice}

Congruence in practice centred on the expectations and experiences of staff mirroring in certain ways the expectations and experiences of pupils. The senior leadership team (SLT) of the school were perceived to work with the staff in ways that were congruent with the school's values. There was a congruence between how SLT treat staff and how staff treat the children. Staff were trusted to take informed risks in their teaching and they in turn enabled the children to take risks in their learning. SLT held high expectations of staff to take responsibility for the part they play in the life of the school and in turn, the staff held high expectations of the pupils to take responsibility for their behaviour. In concrete terms, staff reported that SLT do not disregard, judge or blame staff when there is a difficulty that they need support with, so the staff don't dismiss, judge or blame the children when there is a conflict or behaviour difficulty that they need support with. It can be seen that there was a congruence between what was happening at the structural level of the school and at the agency level of individual staff.

From the top down there was erm there was this whole thing about carrying things through the approach and erm also the support you get from senior managers...so because you are encouraged from senior levels down makes you more confident in your own role as well. (Teaching Assistant) 
It is difficult to know whether these aspects of congruence in practice are the result of changes made by the restorative approaches work or whether they are the school's existing practice. When RA becomes as embedded as it has at this school it can then become difficult to delineate unequivocal lines of causality. Certainly, staff reported on shifts in practice over the time that the school has been working restoratively. This question resonates with a conclusion of the Scottish evaluation, which found that RA can be "a means of giving coherence and identity to established good practices and of further enhancing those practices", or it can represent, "a means of moving the school forward... offering something distinctive" (Kane et al, 2008, p. 248). In this school, the congruence at the level of values would suggest that RA may be providing the coherence and identity indicated above.

\section{Congruence in outcomes}

The benefits of restorative work which the staff reported the children having received were the same benefits that staff had received. Just as restorative conversations had taught the children to be more thoughtful and reflective about their behaviour, so it had made staff more thoughtful and reflective about how they engage with children following an incident of conflict. One Deputy Head described the impact of RP on her, “it's been quite really quite interesting...I don't want to quite say profound, but more than I thought it would. It's led me to conversations... actually you need to dig down so you understand". In this way, staff reported that restorative processes had enabled both children and staff to step back and adopt a calm perspective on conflict situations.

Similarly, the hopes that staff held for the ongoing development of the restorative work at their school were as much for the adults as for the children. Just as the staff want the children to recognise that their feelings are real and transient, so they wanted this for themselves. At a staff level this was expressed as a desire for adults to 
be able to be authentic and therefore honest about when it is not working for them, when they are either unable or unwilling to engage in a restorative process. For example, one teacher's comment that, "If you've been rude and made me cross we're not discussing why you were feeling rude" led on to discussion about the importance of adults recognising the realness and transience of their own feelings.

\section{Incongruence}

In apparent contrast to the theme of congruence, there also emerged an interesting dimension, which can be called incongruence. Analysis of the individual interviews and the group sessions revealed the essential coexistence of apparently mutually excluding elements, e.g. flexible consistency, supported responsibility and gentle strength.

Whilst consistency is often reported as an essential element in the successful implementation of any new initiative, in this instance the staff interestingly presented a nuanced take on consistency, one that incorporates what may for some be a contradictory element, flexibility. Whilst they acknowledged the usefulness of having a defined and clear behaviour system that can facilitate consistency, this had to contain the scope for staff to be responsive to the immediate factors they faced. They stressed the importance of allowing staff to be responsive in dealing with different manifestations of conflict in the school, to use their personal and professional judgment.

This finding is of interest both in terms of the role of professional judgment in working with evidence-supported interventions, and in terms of programme evaluation in schools. The staff contributions on this point indicate that they consider it essential for there to be the space for individual professional judgment in applying interventions and systems in school. The fact that a programme or intervention has an evidence-base vouching for its effectiveness does not therefore remove the need for individual professional judgment. This perspective resonates with Gert Biesta's declaration that 
evidence about the effectiveness of a programme "may have the possibility to inform our judgments [but] it cannot replace our judgments about what needs to be done" (2012, p. 16, italics in original). The staff who engaged in this small-scale study considered the possibility to apply their professional judgment to be essential.

The question then arises, how can professional judgment be enabled within often highly regulated school settings? With its focus on the agency of individuals, it can be argued that restorative practice offers opportunities for individuals to take more responsibility for their particular situations. Indeed, it could be that adoption of RA by a school both promotes and requires increased levels of professional judgment on the part of individual staff, and may of itself create the flexibility required of the school structures for this to happen. It would appear that this tension between individual professional judgment and the strictness of the school structures is one that is brought to the fore with RA.

In terms of evaluation, this finding regarding incongruence may suggest that it is important to incorporate more open research methods in order to gain a more nuanced understanding of how programmes such as RA evolve within the complexity of schools systems. Education researchers and evaluators are increasingly engaging with the challenge of complexity (see Osberg \& Biesta, 2010). Alongside AI, realist evaluation (Pawson \& Tilley, 1997) is one example of an evaluation methodology that may offer potential in drawing out a more nuanced picture of the workings of programmes in complex school settings. "Realist evaluation asks not, 'What works?' or, 'Does this program work?' but asks instead, 'What works for whom in what circumstances and in what respects, and how?"' (Pawson \& Tilley, 2004, p. 2). In engaging with the complexity of life in schools, research methodologies such as AI and realist evaluation 
may offer evaluators useful options to meaningfully and robustly assess the value of education programmes.

\section{When, how and why it works}

This evaluation foregrounded the voices, stories and perspectives of the school's staff. In this way it gave a practice-focused account of how restorative practice has been implemented within a school. This account provides interesting details about when, how and why restorative practice works well and also an insight into reasons and instances when restorative practice is either not appropriate or not possible.

Staff identified certain skills as essential to successful restorative practice. Interestingly, whilst on the one hand these skills were deemed essential for a restorative process to be successful, on the other hand the restorative processes were considered to be effective in developing those same skills. For example, a participant in a restorative process needs to be able to listen to another's perspective in order to engage successfully. At the same time, engagement in a restorative process helps to develop a person's ability to listen to another's perspective. The skills identified included speaking and listening, thinking and reflection, emotional intelligence, conflict resolution and problem-solving.

It was from this identification of the skills required for effective restorative practice that a 10-step framework of restorative practice emerged. Restorative practice gives everybody the opportunity to:
(1) Stop
(2) Step back
(3) Reflect
(4) Talk 
(5) Listen

(6) Question

(7) Understand

(8) Repair

(9) Let it go

(10) Move on

Having emerged from their joint reflection, the 10-step process was enthusiastically discussed by the staff, and they began to develop ideas about how these 10 steps could be used in practical ways with staff and children to provide a more easily understandable framework for restorative processes.

\section{When and why it doesn't work}

Concerns have been expressed that $\mathrm{AI}$ as an evaluation methodology, with its apparently oxymoronic combination of appreciation and evaluation, is only capable of drawing out the positives of the programme being evaluated (Grant \& Humphries, 2006). However, this appreciative evaluation, in line with many others (e.g. Elliot, 1999), drew out some of the limitations of the programme, largely because the trusting and assets-focus of the methodology appeared to enable the staff to be honest about their experiences. In this vein, one particularly interesting topic that emerged was people's 'guilt' at not responding restoratively to conflict all the time. During the group session, one member of staff 'confessed' that she did not use a restorative response as much as she knew she should. This 'confession' opened up an engaged and frank discussion about when and why a restorative response is either not appropriate or not possible. 
The group explored some factors that might indicate why a child or an adult might be unwilling or unable to engage in a restorative process. Could a child's inability or unwillingness to engage with a restorative process be due to her poor self-esteem where she is unable to take more responsibility onto her already burdened shoulders? Could a member of staff's inability or unwillingness to engage in the process at that time be due to his low emotional intelligence? The staff concluded that there are certain factors that can indicate that a restorative response in either not possible or not appropriate. The identified factors included the emotional state of the child or the member of staff; low self-esteem; lack of confidence or competence of the member of staff; lack of time or physical space.

This group of staff then identified a range of strategies and resources on which they might call to overcome some of the identified barriers. These strategies included having a core of highly skilled staff on whom to call for support; the school to develop a shared bank of resources and ideas for how they support the children to develop restorative skills; and a renewed focus on emotional intelligence within staff development. Finally, staff at this school agreed that whilst it was important to work restoratively as much as possible, it was also important for staff to be able to be honest if there are times when they are either unwilling or unable to engage in a restorative response.

These findings are a challenge to RA advocates on many levels. On one level, it is concerning that the humanistic model of behaviour and relationship support that RA represents can engender feelings of guilt and inadequacy on the part of hard-working school staff. On another level, is the conclusion of this staff team that it is not always appropriate or necessary to respond to incidents of conflict in a restorative way a limitation in the practice at this school or an articulation of a natural boundary of 
restorative practice in schools as complex systems? These questions would benefit from further exploration in future studies, and they are aligned with discussion in the literature around the limits of RP in schools, whether they are a tool that can be used or whether RP equates to culture change (Morrison \& Vaandering, 2012).

\section{Conclusion}

In summary the higher-level outcomes reported in this evaluation are the impact of RA on climate for learning, life skills, emotional literacy, behaviour and relationships more broadly, and more specifically the impact on speaking, listening, thinking and conflict resolution. These broader dimensions can be seen to be consistent with the outcomes reported in the three most widely cited evaluations of RA in schools in the United Kingdom mentioned earlier (YJB, 2004; Kane et al., 2008; Skinns et al., 2009). Kane et al reported in depth on the bidirectional relationship between RA values and school ethos. Skinns et al reported on "Improved emotional literacy of staff, but particularly pupils (e.g. their ability to empathise and to take responsibility for their actions)" (p.iii); they also reported an improvement to the climate for learning in schools.

What this AI evaluation of RA at this one primary school may offer is a more nuanced and practice-informed picture of some of the details of implementation and impact in a complex school context. The importance of congruence is a useful and interesting finding that may resonate with restorative advocates and practitioners in schools. In some ways, it reflects what educators often refer to as modelling, but this evaluation unearthed a deeper level of congruence. Congruence goes beyond modelling the behaviour we wish to see in others, it connects our values with our behaviours, and it connects individuals' agency with the structures of which they are a part.

Additionally, congruence carries a broader sense of democratic aspiration, what the staff here want for their pupils they also want for themselves. 
The complexities of working in vibrant school contexts challenge the value of any simplistic conclusions about educational programmes that 'work' or 'don't work' (Biesta, 2007). This evaluation may be useful in offering some initial clues as to how school staff engage with the high-flown principles of restorative practice in the midst of a demanding and vital school context. The concerns raised by these school staff about their inability or unwillingness to engage with RA at times represent a challenge to advocates of restorative practice. It will be by engaging with these concerns in genuinely restorative ways that restorative practice in schools can be more honestly understood and thereby more sustainably supported and developed for the benefits of all members of school communities.

\section{References:}

Biesta, G.J.J. (2007). Why 'what works' won't work. Evidence-based practice and the democratic deficit of educational research, Educational Theory, 57, pp. 1-22.

Biesta, G.J.J. (2010). The future of teacher education: evidence, competence or wisdom?, Research on Steiner Education, 3(1), pp. 8-21.

Coghlan, A.T., Preskill, H. \& Tzavaras Catsambas, T. (2003). An overview of appreciative inquiry in evaluation. New directions for evaluation, 100, 5-22.

Corrigan, M. (2012). Restorative Practices in NZ: The Evidence Base. Ministry of Education.

Cremin, H.C. (2013). Critical perspectives on restorative justice/restorative approaches in schools. In E., Sellman, H. Cremin, and G. McCluskey (eds.), Restorative Approaches to Conflict in Schools: interdisciplinary perspectives on whole school approaches to managing relationships (pp. 109-122). London: Routledge.

Elliott, C. (1999). Locating the Energy for Change: An Introduction to Appreciative Inquiry. Winnipeg: International Institute for Sustainable Development. Retrieved from http://wgbis.ces.iisc.ernet.in/biodiversity/sdev/appreciativeinquiry.pdf.

Grant, S. \& Humphries, M. (2006). Critical evaluation of appreciative inquiry: Bridging an apparent paradox. Action Research, 4(4), 401-418. 
Jacobsgaard, (2003). Using Appreciative Inquiry to Evaluate Project Activities of a Nongovernmental Organization Supporting Victims of Trauma in Sri Lanka, New Directions for Evaluation, 2003(100), 53-62.

Kane, J., Lloyd, G., McCluskey, G., Riddell, S., Stead, J. \& Weedon, E. (2008). Collaborative evaluation: balancing rigour and relevance in a research study of restorative approaches in schools in Scotland, International Journal of Research \& Method in Education, 31(2) 99-111.

King, N., \& Horrocks, C. (2010). Interviews in qualitative research. London: Sage.

McCluskey, G., Lloyd, G., Kane, J., Riddell, S., Stead, J. \& Weedon, E. (2008). Can restorative practices in schools make a difference? Educational Review 60(4) 405-417.

Morrison, B. (2007). Restoring Safe School Communities: A Whole School Response to Bullying, Violence and Alienation. Annandale, NSW: The Federation Press.

Morrison, B.E. \& Vaandering, D. (2012). Restorative Justice: Pedagogy, Praxis, and Discipline, Journal of School Violence, 11(2), 138-155.

Neuman, W.L. (2011). Social Research Methods: Qualitative and Quantitative Approaches, ( $7^{\text {th }}$ edition). Pearson.

Osberg D.C. \& Biesta GJJ (2010). Complexity Theory and the Politics of Education Rotterdam, Sense.

Patton, M. Q. (2003). Inquiry into appreciative evaluation. New Directions for Evaluation, 2003(100), 85-98.

Pawson, R. and Tilley, N. (1997). Realistic Evaluation. London: Sage.

Pawson \& Tilley, 2004. Realist Evaluation. Retrieved from http://www.communitymatters.com.au/RE_chapter.pdf

Pole, C.J. (1993). Assessing and recording achievement. Buckingham: Open University Press.

Skinns, L., Du Rose, N. \& Hough, M. (2009). An evaluation of Bristol RAiS. London: Institute for Criminal Policy Research, King's College London.

Thorsborne, M. \& Vinegrad, D. (2006) Restorative Practices in Schools: Rethinking Behaviour Management. 2nd Edition.

Youth Justice Board for England and Wales (2004). National evaluation of the restorative justice in schools programme. Retrieved from http://www.restorativejustice.org.uk/resource/national_evaluation_of_the_restorative_ju stice_in_schools_programme/\#.ULaJfIf3KSo.

Zehr, H. (2002). The Little Book of Restorative Justice. Intercourse, PA: Good Books. 